\title{
Specialized Aviation Flight Accreditation under Public Law 111-216: Aviation Program Administrators' Perceptions
}

\author{
Cody Christensen \\ South Dakota State University \\ Karen A. Card \\ University of South Dakota
}

\begin{abstract}
Under Public Law 111-216, program integrity and quality assurance of collegiate aviation programs were questioned (Airline Safety and Federal Aviation Administration Extension Act of 2010, 2012). The goal of this study was to update the field of specialized aviation accreditation in the new environment of the Airline Safety and Federal Aviation Administration Extension Act of 2010 and outcomes-based accreditation (Aviation Accreditation Board International, 2013). This is in response to the Sherman (2006) and Prather (2007) studies on why so few of the schools offering aviation-related curricula leading to an associate's or bachelor's degree seek specialized accreditation. The purpose of this study was to determine if aviation administrators perceive AABI outcomes as important and how effectively their programs prepared aviation graduates with competences in the accreditation outcomes. Additionally, this study addresses the level of academic studies that program administrators feel can substitute for flight time as outlined in the Notice of Proposed Rulemaking on Public Law 111-216. Administrators perceived AABI Core Outcomes - aircraft characteristics as well as meteorology and environmental issues - to be important and that their program was effectively teaching these competences. Administrators generally agreed that five hundred hours was an appropriate amount of time to credit a graduate of a four-year aviation program seeking a Reduced Airline Transport Pilot certificate, regardless of AABI accreditation status, which is the maximum time reduction for collegiate aviation students under the Reduced Airline Transport Pilot criteria published in 2013.
\end{abstract}

\section{Introduction}

The Airline Safety and Federal Aviation Administration Extension Act of 2010, a legislative mandate in response to the 2009 crash of Colgan Air Flight 3407, made a dramatic change in the job outlook of students in collegiate aviation. The Act essentially increased the flight time required to fly as a required crewmember in an airline environment from 250 hours to 1,500 hours. Also impacting collegiate aviation are the changes to specialized aviation accreditation that have taken place. In the last 10 years, the Aviation Accreditation Board International changed the accreditation criteria to outcomes-based accreditation. As a result of the FAA Extension Act of 2010 and outcomes-based accreditation, this study was conducted to identify what program administrators of 
collegiate aviation programs perceived as the impact of the Extension Act and accreditation on their programs. For this study, program administrators are defined as individuals who directly manage an aviation unit, including program chairs, department heads, program leaders, and supervisors.

Both the pilot training portion of the FAA Extension Act of 2010 and Aviation Accreditation Board International (2013) specialized accreditation essentially serve the same purpose - to produce highly competent aviation professionals. This study was limited to data collected in early 2013, after the enactment of the FAA Extension Act of 2010, which required all airline pilots to possess an Airline Transport Pilot certificate, but before the final ruling from the FAA in Advisory Circular 61.139 (2013). This study concluded before the FAA Administrator's provision, the Airline Transport Pilot Certification Training Program (2013), which allowed a reduction in total flight hours required for an ATP certificate.

One of the steps the FAA requires as part of the Reduced Airline Transport Certification process is to demonstrate completion of approved coursework in an approved higher education curriculum. Essentially, the FAA is determining that coursework completed by students pursuing the ATP can be used in lieu of some of the flight time requirement. On the other hand, AABI accreditation requires that graduates of accredited programs demonstrate proficiency in knowledge, skills, and attitudes before they can graduate.

The first purpose of this study was to determine aviation administrators' perception of outcomes in preparing professional pilots and the extent to which their programs effectively achieve the Aviation Accreditation Board International standards. Additionally, this study determined aviation program directors' perceptions regarding the level of academic studies that can substitute for flight time as outlined in the Notice of Proposed Rule Making (NPRM) on Public Law 111-216. Lastly, this study determined the extent to which the new Airline Safety and Federal Aviation Administration Extension Act of 2010 influenced administrators' decisions to seek specialized aviation accreditation.

\section{Review of Relevant Literature and Research}

While studies exist on specialized accreditation, only two authors-Sherman (2006) and Prather (2007) - specifically looked at the programs' willingness to participate in or barriers to aviation accreditation from a faculty standpoint. This study mirrored Prather's (2007) study with implication of AABI accreditation since the inception of Public Law 111-216 and before the final ruling from the FAA regarding the Reduced Airline Transport Pilot minimums guidance provided in Advisory Curricular 61.139 (2013). Another purpose of this study was to further the knowledge base on specialized aviation accreditation since Radigan's (2011) study on students' perceptions of aviation accreditation. This study looked at the individual outcomes of AABI and how aviation administrations perceived what standards are important and how effectively their program prepared aviation graduates with competences in the accreditation outcomes. 
Sherman (2006) wanted to find answers to why faculty and administrators sought accreditation, time required for the accreditation process, and the use of human resources to complete the self-study. In his qualitative study, he surveyed faculty and administrators of aviation programs belonging to the University Aviation Association and by using the 2006 AOPA collegiate flight training issue.

From his research, Sherman concluded that current AABI accredited programs believe in AABI accreditation and have many reasons for their belief, including enhancing the quality of programs, prestige, and benefits of the external review process. His findings regarding why non-AABI accredited programs did not seek accreditation included lack of awareness among industry and students, the expense and time involved with the accreditation process, and the fact that many programs felt the standards only applied to larger programs.

Prather (2007) conducted research regarding why so few aviation programs sought accreditation through $\mathrm{AABI}$ and its precursor, the Council on Aviation Accreditation (CAA). Prather reported from the survey results that $65 \%$ of current non-AABI accredited aviation programs plan to seek accreditation in the future. He also found that the primary reason for not seeking accreditation included the time/expense/effort versus benefits of being accredited. Additionally, non-AABI accredited programs chose not to accredit because they had a similar accreditation already, lacked awareness of AABI, and, most interestingly, some programs felt they did not need to accredit their programs because their graduates were currently successful (Prather, 2006). He also pointed out that by maintaining accreditation, programs benefit from the rigors of an externally reviewed selfstudy process.

Radigan (2011) addressed specific questions regarding students' perceptions of quality in collegiate aviation based on accredited versus non-accredited programs. This research indicated that students of accredited programs perceive their education as being of higher quality than that of non-AABI accredited schools. She also observed, based on her findings, that "student perceptions of quality for curriculum and facilities and equipment are significantly higher in accredited programs" (p. 120).

As noted by the Council for Higher Education Accreditation (CHEA), in order to receive federal financial aid, all universities must be regionally accredited (Council for Higher Education Accreditation, 2002; Eaton \& Council for Higher Education Accreditation, 2006). Aviation programs can either be regionally accredited through a CHEA organization or program accredited by an accreditation agency such as AABI, or 
both. Those flight programs that are AABI (2013) accredited adhere to an outcomes-based accreditation using the following outcomes:

AABI General Outcomes:

a. An ability to apply knowledge of mathematics, science, and applied sciences

b. An ability to analyze and interpret data

c. An ability to function on multi-disciplinary teams

d. An understanding of professional and ethical responsibility

e. An ability to communicate effectively, including both written and verbal communication skills

f. A recognition of the need for, and an ability to engage in, life-long learning

g. A knowledge of contemporary issues

h. An ability to use the techniques, skills, and modern technology necessary for professional practice

i. An understanding of the national and international aviation environment

j. An ability to apply pertinent knowledge in identifying and solving problems

$\mathrm{k}$. An ability to apply knowledge of business sustainability to aviation issues

\section{AABI Core Outcomes:}

1. Attributes of an aviation professional, career planning, and certification

2. Aircraft design, performance, operating characteristics, and maintenance

3. Aviation safety and human factors

4. National and international aviation law and regulations

5. Airports, airspace, and air traffic control

6. Meteorology and environmental issues

Most aviation programs are currently part of a postsecondary educational institution that does meet the U.S. Department of Education's (2013) definition of an accredited institution which is the "recognition that an institution maintains standards requisite for its graduates to gain admission to other reputable institutions of higher learning or to achieve credentials for professional practice" (p. 1). Additionally that means under the proposed rule, a graduate of an accredited four-year post-secondary school who received a bachelor's degree in an aviation-related field and a commercial pilot certificate with an instrument rating from an affiliated Part 141 pilot school would be allowed to apply for the ATP practical test with 1,000 hours total time as a pilot, versus the current requirements of 1,500 total hours (Federal Aviation Administration, 2013).

The timing of this study creates relevance for the topic. Aviation accreditation has never been directly tied to training outcomes that explicitly help or hinder students. The NPRM on Public Law 111-216, in part, provides an incentive to students pursuing a career with the airlines by decreasing the amount of flight time required to qualify to fly in the United States airline environment if they graduated from an accredited institution. The Prather (2007), Sherman (2006), and Radigan (2011) studies took place before the requirements of 
Public Law 111-216 were created. After this study was completed, Depperschmidt (2013) studied the impact of Public Law 111-216 on collegiate aviation and concluded the majority of flight programs have concerns with the new law and its impact on pilots pursuing airline careers in the United States.

\section{Limitations}

This study was delimited to collegiate aviation administrators' perceptions of specialized aviation accreditation across different factors and did not necessarily represent all of the aviation training sectors and cannot be generalized to those that did not participate in the study. The variables chosen to examine were limited to focus the scope of the study to factors of accreditation and Public Law 111-216. The perceptions and results are delimited to early 2013 while the NPRM on Public Law 111-216 was still in effect and before publication of Advisory Circular 61-139 (2013) which specifically addresses the reduced flight time requirement. Another limitation is that the aviation administrators' locations, missions, and sizes create unique environments. Therefore, the standards and perceptions being studied may not be applicable to the same magnitude at each institution, as many aviation flight programs are not accredited. It was important to also include their perceptions in this study because administrators who have not been through one or more accreditation cycles might not have the same insight into AABI Outcomes versus administrators who have been through the full accreditation process. This could limit the administrators' perception as to how qualified they are to measure their effectiveness at meeting each AABI Outcome.

\section{Methodology}

This study was designed to determine aviation program administrators' perceptions of specialized aviation accreditation regarding flight programs under Public Law 111-216. A quantitative methodology was used in this study to guide the following research questions:

1. What relationship exists between aviation administrators' perceptions of the importance of the AABI outcomes and how effective they perceive their programs are in preparing pilot candidates to achieve those standards?

2. To what extent do aviation flight program administrators perceive academic studies can substitute for flight time, as outlined in the NPRM on Public Law $111-216 ?$

3. To what extent has the new the Airline Safety and Federal Aviation Administration Extension Act of 2010 influenced the program administrators' decision to seek specialized aviation accreditation? 


\section{Population}

The population consisted of program administrators of baccalaureate degree-granting aviation programs in the United States and territories. The list was compiled from the Airplane Owners and Pilots Association annual college guide (2012) and cross-listed with the University Aviation Association (2012) database on collegiate aviation programs. In total, 82 aviation program administrators were selected as the population from universities and colleges offering training toward bachelor degrees. In January and February 2013 a survey and follow-up survey were electronically distributed to the population, with 34 program administrators completing the survey (response rate of $41.5 \%$ ).

\section{Research Instrument}

Participants completed a 45-item survey that was developed by the researcher based on the work from Prather (2007), Sherman (2006), and the AABI accreditation general and core outcomes (AABI, 2013). The items included perceptions of the importance and effectiveness of the AABI accreditation outcomes (2013), perceptions on accreditation, and the Airline Safety and Federal Aviation Administration Extension Act of 2010, as well as demographic questions such as program size, accreditation status, and number of faculty. The items were answered by selection of Likert scale, multi-point scales, and one user response box. Descriptive statistics, such as means, percentages, standard deviations, Pearson correlations, and frequencies, were calculated for the variables.

To determine internal consistency, Cronbach's $\alpha$, a coefficient of internal reliability, was applied to the Likert-scale questions (Cronk, 2010). According to Cronk (2010) reliability coefficients close to 1.00 are very good and coefficients close to 0.00 represent low internal reliability. Using SPSS version 22, an $\alpha$ of .947 resulted, indicating a high level of internal reliability.

\section{Results}

The respondents in this study consisted of 34 program administrators from four-year institutions that have an aviation flight program leading to a baccalaureate degree. The program administrators answered demographic questions about their aviation program, including the accreditation status and institutional size, measured both in number of students and of staff. The accreditation status breakdown of the study respondents' programs were $18(52.9 \%)$ accredited or in candidate status by AABI, and $16(47.1 \%)$ not accredited by AABI.

Institutional size was another piece of information collected. There were $15(44.1 \%)$ responses from institutions with fewer than 100 students, $13(38.2 \%)$ responses from institutions with 101-400 students, four (11.8\%) responses from institutions with 401-1000 students, and two $(5.9 \%)$ responses from institutions with 1,001 or more students.

In terms of full-time equivalent (FTE) aviation faculty at each institution, six $(17.7 \%)$ indicated they had greater than 15 faculty, three (8.8\%) indicated they had between 9-15 
faculty, four (11.8\%) indicated they had between 5-8 faculty, and 21 (61.8\%) indicated they had four or fewer FTE faculty on staff at their institution, as shown in Table 1.

Table 1

Demographic of Participants $(n=34)$

\begin{tabular}{lcr}
\hline Characteristics & Frequency & Valid Percent \\
\hline Accreditation Status & & \\
Accredited/candidate status & $\mathbf{1 8}$ & $\mathbf{5 2 . 9}$ \\
$\quad$ Non-accredited status & 16 & 47.1 \\
Number of Aviation Students at Institution & & \\
$<\mathbf{1 0 0}$ & $\mathbf{1 5}$ & $\mathbf{4 4 . 1}$ \\
$101-400$ & 13 & 38.2 \\
$401-1000$ & 4 & 11.8 \\
$>1000$ & 2 & 5.9 \\
Number of Aviation Faculty at Institution & & $\mathbf{6 1 . 8}$ \\
$\mathbf{1}-\mathbf{4}$ FTE & $\mathbf{2 1}$ & 11.8 \\
$5-8$ FTE & 4 & 8.8 \\
$9-15$ FTE & 3 & 17.7 \\
\hline 15 FTE & 6 & \\
\hline
\end{tabular}

Note. Largest groups are bolded.

Overall, aviation program administrators who participated in the survey cited each AABI General and Core Outcome as important to very important. Making professional and ethical decisions $(M=4.79, S D=0.54)$ was the highest AABI General Outcome and aviation safety and human factors $(M=4.58, S D=0.56)$ was the highest AABI Core Outcome. Aviation program administrators cited each of their programs as effective in meeting all AABI General and Core Outcomes. Making professional and ethical decisions was noted as the most effective general outcome $(M=4.09, S D=1.13)$. Program administrators deemed the core outcome on the attributes of an aviation professional, career planning, and certification $(M=4.26, S D=0.93)$ as the most effective outcome.

In order to test the relationship between variables, bivariate correlation was used. According to Cronk (2010) "correlations with an absolute value greater than 0.7 are considered strong. Correlations with an absolute value less than 0.3 are considered weak. Correlations with an absolute value between 0.3 and 0.7 are considered moderate" (p. 42).

There were no significant strong relationships between administrators' perceptions of the AABI General Outcomes they viewed as important and how effective they perceived their programs were in preparing aviation graduates to achieve those outcomes. However, there were eight significant moderate positive relationships between aviation program 
administrators' perceptions of the AABI General Outcomes viewed as important and how effective they perceived their programs were in preparing aviation graduates to achieve those outcomes. The full results for the Pearson correlation coefficient for AABI General Outcomes are illustrated in Table 2.

A significant strong positive relationship was found for how important and effective program administrators feel their programs are for AABI Core Outcomes on aircraft characteristics, $r(31)=.721, p=.000$ and meteorology and environmental issues, $r(31)$ $=.718, p=.000$ as indicated in Table 3 . All of the core outcomes results had moderate significant correlations and eight of the 11 AABI General Outcomes demonstrated a positive moderate correlation between perceived importance and effectiveness at meeting those two outcomes (Table 2).

\section{Academic Substitution}

The second research question probed to what extent aviation program administrators perceive that academic studies can substitute for flight time, as outlined in the NPRM on Public Law 111-216. Aviation program administrators were split on whether academic classroom time can be substituted for flight time for those students pursuing an Airline Transport Pilot certificate. As demonstrated in Table 3, of the respondents $(M=3.35, S D$ $=1.25)$, half agreed to strongly agreed $(50.0 \%, n=17)$ that classroom time can substitute for flight time. Eight (23.5\%) participants were neutral on the subject. 
Table 2

Pearson Correlation for Importance and Effectiveness of AABI General Outcomes

\begin{tabular}{|c|c|c|c|c|c|}
\hline Characteristics of AABI General Outcomes & $M I$ & $M E$ & $r$ & $r^{2}$ & $p$ \\
\hline $\begin{array}{l}\text { Apply knowledge of business sustainability to } \\
\text { aviation issues }(\mathrm{K})\end{array}$ & 3.71 & 3.33 & 0.565 & 0.319 & .001 \\
\hline $\begin{array}{l}\text { Use the techniques, skills, and modern technology } \\
\text { necessary for professional practice }(\mathrm{H})\end{array}$ & 4.44 & 4.06 & 0.524 & 0.275 & .002 \\
\hline $\begin{array}{l}\text { Engage in and recognize of the need for life-long } \\
\text { learning }(\mathrm{F})\end{array}$ & 4.09 & 3.52 & 0.499 & 0.249 & .003 \\
\hline $\begin{array}{l}\text { Assess the national and international aviation } \\
\text { environment (I) }\end{array}$ & 3.79 & 3.34 & 0.493 & 0.243 & .004 \\
\hline Make professional and ethical decisions (D) & 4.79 & 4.09 & 0.439 & 0.193 & .011 \\
\hline $\begin{array}{l}\text { Communicate effectively, using both written and oral } \\
\text { communication skills (E) }\end{array}$ & 4.65 & 3.85 & 0.413 & 0.171 & .017 \\
\hline Assess contemporary issue $(\mathrm{G})$ & 3.88 & 3.56 & 0.391 & 0.153 & .027 \\
\hline Analyze and interpret data (B) & 4.41 & 3.73 & 0.346 & 0.120 & .049 \\
\hline $\begin{array}{l}\text { Apply knowledge of mathematics, science, and } \\
\text { applied sciences (A) }\end{array}$ & 4.38 & 3.94 & 0.317 & 0.100 & .072 \\
\hline $\begin{array}{l}\text { Work effectively on multi-disciplinary and diverse } \\
\text { teams (C) }\end{array}$ & 4.38 & 3.88 & 0.270 & 0.073 & .129 \\
\hline $\begin{array}{l}\text { Apply pertinent knowledge in identifying and solving } \\
\text { problems }(\mathrm{J})\end{array}$ & 4.59 & 3.97 & 0.217 & 0.047 & .226 \\
\hline Characteristics of AABI Core Outcomes & $M I$ & $M E$ & $r$ & $r^{2}$ & $p$ \\
\hline $\begin{array}{l}\text { Aircraft design, performance, operating } \\
\text { characteristics, and maintenance (2) }\end{array}$ & 3.55 & 3.53 & 0.721 & 0.520 & .000 \\
\hline Meteorology and environmental issues (6) & 4.00 & 3.85 & 0.718 & 0.516 & .000 \\
\hline $\begin{array}{l}\text { National and international aviation law, regulations, } \\
\text { and labor issues (4) }\end{array}$ & 3.67 & 3.59 & 0.698 & 0.487 & .000 \\
\hline Airports, airspace, and air traffic control (5) & 4.18 & 4.18 & 0.646 & 0.417 & .000 \\
\hline $\begin{array}{l}\text { Attributes of an aviation professional, career planning, } \\
\text { and certification (1) }\end{array}$ & 4.48 & 4.26 & 0.594 & 0.353 & .000 \\
\hline Aviation safety and human factors (3) & 4.58 & 4.24 & 0.457 & 0.209 & .008 \\
\hline
\end{tabular}


Table 3

Classroom Time Substituting for Flight Time and Extension Act Influence on Seeking Accreditation

\begin{tabular}{|c|c|c|c|c|c|c|}
\hline Likert-Scale Statement & $\begin{array}{l}\text { Strongly } \\
\text { Disagree }\end{array}$ & Disagree & Neutral & Agree & $\begin{array}{l}\text { Strongly } \\
\text { Agree }\end{array}$ & $\mathrm{M}(\mathrm{SD})$ \\
\hline $\begin{array}{l}\text { Classroom time can } \\
\text { substitute for flight } \\
\text { time for students } \\
\text { pursuing the Airline } \\
\text { Transport Pilot Rating } \\
(\mathrm{n}=34)\end{array}$ & $\begin{array}{c}3 \\
(8.8 \%)\end{array}$ & $\begin{array}{c}6 \\
(17.6 \%)\end{array}$ & $\begin{array}{c}8 \\
(23.5 \%)\end{array}$ & $\begin{array}{c}10 \\
(29.4 \%)\end{array}$ & $\begin{array}{c}7 \\
(20.6 \%)\end{array}$ & $\begin{array}{c}3.35 \\
(1.25)\end{array}$ \\
\hline $\begin{array}{l}\text { Influence of the } \\
\text { Airline Safety and } \\
\text { Federal Aviation } \\
\text { Administration } \\
\text { Extension Act of } 2010 \\
\text { on Seeking AABI } \\
\text { accreditation }(\mathrm{n}=33)\end{array}$ & $\begin{array}{c}10 \\
(30.3 \%)\end{array}$ & $\begin{array}{c}6 \\
(18.2 \%)\end{array}$ & $\begin{array}{c}11 \\
(33.3 \%)\end{array}$ & $\begin{array}{c}3 \\
(9.1 \%)\end{array}$ & $\begin{array}{c}3 \\
(9.1 \%)\end{array}$ & $\begin{array}{c}2.48 \\
(1.28)\end{array}$ \\
\hline $\begin{array}{l}\text { Influence of the } \\
\text { Airline Safety and } \\
\text { Federal Aviation } \\
\text { Administration } \\
\text { Extension Act of } 2010 \\
\text { on Seeking any } \\
\text { accreditation }(\mathrm{n}=34)\end{array}$ & $\begin{array}{c}10 \\
(29.4 \%)\end{array}$ & $\begin{array}{c}7 \\
(20.6 \%)\end{array}$ & $\begin{array}{c}10 \\
(29.4 \%)\end{array}$ & $\begin{array}{c}5 \\
(14.7 \%)\end{array}$ & $\begin{array}{c}2 \\
(5.9 \%)\end{array}$ & $\begin{array}{c}2.47 \\
(1.24)\end{array}$ \\
\hline
\end{tabular}

A follow-up question was asked to determine how many flight hours would be appropriate to substitute classroom time for flight time for students pursuing the ATP certificate. As displayed in Table 4, of the 32 responses $(M=2.41, S D=0.91), 46.9 \%$ believe between 1-500 hours is the appropriate amount of time, followed by $31.3 \%$ who believe 501-750 hours is an appropriate amount to count as flight time under the new regulations. 
Table 4

Specific Hours of Classroom Time Substituting for Flight Time for Students Pursuing an ATP

\begin{tabular}{lcc}
\hline & Response Number & Valid Percent \\
\hline Zero hours & 4 & 12.5 \\
$1-500$ hours & 15 & 46.9 \\
$501-750$ hours & 10 & 31.3 \\
$751-1000$ hours & 2 & 6.3 \\
$>1000$ hours & 1 & 3.1 \\
Mean & 32 & 2.41 \\
Standard Deviation & & 0.91 \\
\hline
\end{tabular}

\section{Decision to Seek Accreditation}

The third research question asked if the Airline Safety and Federal Aviation Administration Extension Act of 2010 influenced administrators' decisions to seek accreditation. Two questions on the survey presented participants with opportunity to voice their opinions as to how strongly they felt the Airline Safety and Federal Aviation Administration Extension Act of 2010 influenced their decision to seek accreditation. Participants were most often neutral $(M=2.48, S D=1.28)$, followed by disagreeing as to whether the Airline Safety and Federal Aviation Administration Extension Act of 2010 influenced their decision to seek AABI specialized accreditation as noted in Table 5. The second question revealed that many $(M=2.47, S D=1.24)$ of the participants did not feel that the Airline Safety and Federal Aviation Administration Extension Act of 2010 had any influence on their decision to seek any accreditation as shown in Table 3.

\section{Discussion}

Utilizing the population of just aviation program administrators, AABI General and Core Outcomes appear to be important objectives, and collegiate aviation programs should work to incorporate those outcomes into their curricula. The results of this study seem to indicate that regardless of specialized accreditation status, programs utilizing demonstrated outcomes contribute to producing highly competent aviation professionals, which is different than course content inputs that the FAA is certifying as part of the Institution of Higher Education's Application for Authority to Certify its Graduates for an Airline Transport Pilot Certificate with Reduced Aeronautical Experience 61.139 (2013). Program administrators perceive that graduates of four-year collegiate aviation programs meet most 
of the AABI Outcomes whether they were AABI accredited or not AABI accredited. This could signify that specialized aviation accreditation status may not be needed as an indicator of quality of a program or, more likely, that administers of non-accredited programs are unaware of the benefits provided through the full AABI accreditation cycle. Again, this study was looking at administers' perspectives on accreditation and did not take into account the rigorous process that ensures that programs meet AABI outcomes.

Making professional and ethical decisions and aviation safety and human factors were the highest cited AABI General and Core Outcomes, respectively. Since the enactment of the FAA Extension Act of 2010 and the Colgan accident in 2009, ethics in aviation and especially professionalism have taken center stage. This is indicated by program administrators citing decision-making skills and aviation safety and human factors as the most important $\mathrm{AABI}$ requirements.

Program administrators were also asked about how effective their specific program was at meeting each AABI General and Core Outcomes. Through this process each administrator answered that they perceived their programs were effective at meeting each AABI outcome. Previous studies have indicated that some program outcomes were not aligned with $\mathrm{AABI}$ outcomes and cited other factors for not seeking accreditation, such as financial resources, as a barrier to AABI accreditation (Prather, 2007; Sherman, 2006). It is important for program administrators and all stakeholders of both AABI accredited and non-accredited aviation programs to graduate high-quality aviation professionals.

While this study did not examine barriers to accreditation, it appears that the majority of the programs, both accredited and non-accredited, are perceived by their program administrators as effectively meeting AABI criteria and that they believe that AABI criteria are important for graduates of their programs. If program administrators of non-accredited program perceive that their program meets AABI General and Core Outcomes then these programs should go through the accreditation process for the benefit of their students and the profession. This indicates a paradigm shift in outcomes as not being a barrier to accreditation as they once were under the standards-based accreditation system of the past, as noted by Sherman (2006) and Prather (2007). This is different than the current guidelines set forth by the FAA in Advisory Circular 61.139 (2013) which states that "a graduate complete a specific number of credit hours in aviation coursework that has been recognized by the FAA as coursework designed to improve and enhance the knowledge and skills of a person seeking a career as a professional pilot," (p. 6). Because it appears that the FAA standards are being met, program leaders should reevaluate AABI accreditation as a way to provide external validation of their programs' quality to prospective students and governing boards should use AABI accreditation status as another means to verify that graduates are prepared as professional pilots.

Program administrators believe it is appropriate to substitute academic hours for minimum flight time requirements for students pursuing the Airline Transport Pilot certificate. From the study's results it is apparent that administrators of aviation programs feel that classroom time gathered in a collegiate aviation program can be substituted for 
flight time, which falls in line with the recommendation outlined in the NPRM on Public Law 111-216 (2010) and 14 CFR 61.160 aeronautical experience-airplane category restricted privileges (Federal Aviation Administration, 2013). The respondents disagreed that only graduates of AABI accredited programs should receive a decrease in flight time, and the FAA requirements are in keeping with that position in allowing all accredited schools, not just AABI accredited schools, to participate in the reduction of flight time.

When administrators were asked how much classroom time can substitute for flight time, the majority agreed or strongly agreed (61.8\%) with the question asked that 500 hours is an appropriate reduction in flight time for graduates of four-year aviation programs. Interestingly, almost half of the administrators $(46.9 \%, n=32)$ surveyed cited that between $1-500$ hours is the appropriate amount of time to substitute while almost one third $(31.3 \%$, $n=32$ ) felt that between 501-750 hours was an appropriate amount of classroom time to substitute for flight time. After the data were collected, the FAA specified in 14 CFR 61.160 (2013) that 500 hours was the maximum amount of reduction for graduates of approved curriculum associated with Bachelor degree granting institutions, and issued a letter of authorization for the reduction in flight time. As this survey data was collected before the final ruling of 14 CFR 61.160, the researcher limited participants' choices, which did influence how respondents could answer the question. Additional information is needed to determine if the 500-hour reduction in flight time is perceived as the proper amount.

Lastly, this study determined the extent to which the Airline Safety and Federal Aviation Administration Extension Act of 2010 influenced administrators' decisions to seek specialized aviation accreditation. Program administrators were neutral as to whether the Airline Safety and Federal Aviation Administration Act of 2010 influenced a decision to seek AABI specialized accreditation. Most were in agreement that the Extension Act of 2010 did not influence their decision to seek any accreditation.

Based on the findings, programs that train graduates for careers in the field of aviation should follow the AABI General and Core outcomes as they are peer reviewed and have validated outcomes associated with high level programs. While each program operates differently and has inherently different outcomes, producing a high-quality, safetyorientated aviation professional should be a mainstay for all programs. The FAA approached the purpose of an approved curriculum as a way to improve and enhance the knowledge and skills of a professional pilot, but it did not take into account any outcomes of those courses.

While the FAA did not take into account AABI accreditation standards in preparing the Advisory Circular outlining the eight academic areas graduates must meet, all of the content requirements outlined in AC 61-139 (2013) are met by AABI Flight Education programs (Aviation Accreditation Board International, 2013). AABI outcomes-based accreditation could serve as a model for the new FAA guidelines as a way to verify that 
the outcomes of the courses are appropriate for preparing a professional pilot and not just the inputs of coursework.

\section{Conclusion and Further Research}

Additional research is needed on perceptions of how exactly this new rule will be assessed and providing the necessary outcomes expected from the FAA. Potential research could include outcomes-based accreditation in light of the new FAA R-ATP guidelines as a way to assess the validity of Public Law 111-216 and the FAA's Reduced Airline Transport Pilot criteria. Also, researching perceptions of accreditation under PL 111-216 from additional stakeholders such as current students, graduates, aviation professionals, and administrators would help to better understand how AABI could benefit or provide greater clarification to the outcomes proposed by PL 111-216.

This research determined that aviation program administrators recognized AABI Outcomes as important and identified their aviation programs as being effective at meeting most of the AABI Outcomes. Additionally, most administrators agreed that classroom time can substitute for flight time for those students pursing the ATP requirements, with 500 hours deemed as an appropriate amount to credit as adopted by the FAA. It is also important to note that the Airline Safety and FAA Extension Act of 2010 did not generally influence program leaders' decisions to gain regional or specialized (AABI) accreditation. Most universities with flight programs are in the process or have already submitted for a reduction in flight time under $\mathrm{AC}$ 61-139, which means that many of the standards already in place by collegiate aviation programs did not have to change. The next step for the FAA will be to determine whether the attributes and skills it perceived as important are in fact being effectively carried out under the Reduced Airline Transport Pilot training criteria. 


\section{References}

Airline Transport Pilot Certification Training Program. (2013). Retrieved from http://www.faa.gov/regulations_policies/advisory_circulars/index.cfm/go/document.i nformation/documentID/1021128

Airline Safety and Federal Aviation Administration Extension Act of 2010, 216 C.F.R. (2012). Retreived from http://www.faa.gov/regulations_policies/rulemaking/recently_published/media/2120 -AJ67NPRM.pdf

AOPA. (2012). 2013 College aviation directory. AOPA Flight Training.Retrieved from http://flighttraining.aopa.org/magazine/2012/December/feature-schools.html

Aviation Accreditation Board International. (2013). Retrieved from http://www.aabi.aero/

Council for Higher Education Accreditation. (2002). Council for Higher Education Accreditation Fact Sheets \#1-5. Washington D. C.

Cronk, B. C. (2010). How to use PASW statistics: A step-by-step guide to analysis and interpretation. (6th ed.). Glendale, CA: Pyrczak.

Depperschmidt, C. L. (2013). Public Law 111-216: Effects of new legislation on collegiate aviation flight training programs. Collegiate Aviation Review, 31(1), 1-16.

Eaton, J. S., \& Council for Higher Education Accreditation, W. D. C. (2006). An Overview of U.S. Accreditation: Council for Higher Education Accreditation. Retrieved from http://www.chea.org/pdf/2009.06_Overview_of_US_Accreditation.pdf

Federal Aviation Administration. (2013). Institution of higher education's application for authority to certify its graduates for an Airline Transport Pilot Certificate with reduced aeronautical experience. Washington, D.C.: Federal Register Retrieved from http://www.faa.gov/documentLibrary/media/Advisory_Circular/AC_61139.pdf.

Prather, C. D. (2006). The council of aviation accreditation: Part two--contemporary issues. Journal of Air Transportation, 11(3), 34-60. 
Prather, C. D. (2007). Specialized accreditation in collegiate aviation: An analysis of the perceived value of specialized accreditation by the aviation accreditation board international. (Doctoral dissertation), University of Nebraska Lincoln. Retrieved from

http://digitalcommons.unl.edu/cgi/viewcontent.cgi?article $=1017 \&$ context $=$ cehsdiss

Radigan, J. A. (2011). Student perceptions of quality in collegiate aviation: A comparative analysis of accredited and non-accredited institutions. (Educational Doctorate dissertation), Dowling College. Retrieved from Dissertations \& Theses: Full Text.(Publication No. AAT 3462948) Available from ProQuest

Sherman, M. A. (2006). A qualitative study of collegiate aviation institutions and the collegiate aviation accreditation process. (Doctorate of Education Dissertation), Oklahoma State University, Stillwater.

University Aviation Association. (2012). University Aviation Association. Retrieved from http://www.uaa.aero/

U.S. Department of Education. (2013). FAQ's about Accreditation. Retrieved from http://ope.ed.gov/accreditation/faqaccr.aspx 